\title{
El delito de impago de prestaciones por separación, divorcio o nulidad de matrimonio
}

\author{
Blas Jesús Imbroda Ortiz \\ Profesor-Tutor de Derecho Penal \\ Abogado
}

Nos encontramos ante una de las novedades que incorpora la reforma promovida por la Ley Orgánica 3/1989, de 21 de junio, de actualización del Código Penal.

Controvertido y criticado desde su incorporación al Código Penal, voy a efectuar un estudio de las líneas generales en que se configura este delito.

El artículo 487 bis del Código Penal dispone: "El que dejare de pagar durante tres meses consecutivos o seis meses no consecutivos cualquier tipo de prestación económica en favor de su cónyuge o sus hijos, establecida en convenio judicialmente aprobado o resolución judicial, en los supuestos de separación legal, divorcio o declaración de nulidad del matrimonio, será castigado con la pena de arresto mayor y multa de 100.000 a 500.000 ptas.".

\section{Antecedentes y cuestiones previas}

No se encuentran antecedentes en los distintos Códigos Penales españoles sobre la existencia de este delito o uno afín.

En el Código Penal de 1944 se regula el artículo 487 del abandono de familia y en su penúltimo párrafo castigaba cuando el cónyuge culpable del abandono "dejare de prestar la asistencia indispensable para el sustento, a sus descendientes menores o incapaces para el trabajo, o a sus ascendientes o cónyuge que se hallaren necesitados, a no ser respecto al último que estuvieren separados por culpa (por causa 
imputable, en la actual redacción) del referido cónyuge, será castigado con la pena de arresto mayor en su grado máximo y multa de 5.000 a 10.000 ptas. (actualmente de 100.000 a 1.000 .000 ptas.) Precepto que sustancialmente perdura en la actualidad. No obstante, el nuevo artículo 487 bis ha pretendido incriminar hechos más allá de lo tipificado en el delito de abandono de familia y en otros tipos que como veremos más adelante podrían estar encuadradas las conductas del también llamado delito de impago de prestaciones económicas.

Como precedente de este nuevo precepto, en nuestra legislación se encuentra el artículo 34 de la Ley de Divorcio de 12 de Mayo de 1932 que establecía:

"el cónyuge divorciado que viniendo obligado a prestar pensión alimenticia al otro cónyuge o a los descendientes, en virtud de convenio judicialmente aprobado o de resolución judicial, y que culpablemente dejara de pagarla durante tres meses consecutivos, incurrirá en la pena de prisión de tres meses a un año o multa de 500 a 10.000 ptas. La reincidencia se castigará en todo caso con pena de prisión".

La Ley de 7 de Julio de 1981 que reforma el Código Civil, permite el divorcio por primera vez en nuestro país (excepción de la corta experiencia de la Ley de Divorcio de la Segunda República), estableciendo las causas de separación, divorcio y nulidad del matrimonio, ello con las consecuentes medidas y efectos para estas situaciones en las que se van a encontrar cónyuges y en su caso hijos.

Los nuevos artículos del Código Civil, establecen la pensión compensatoria y la pensión alimenticia, a las que más adelante nos referiremos.

La experiencia en estos años de aplicación de la nueva normativa en materia matrimonial, ha generado los lógicos problemas que la práctica jurídica conlleva.

Uno de ellos, y que por afectar al sustento y mantenimiento de las personas, ha levantado más polémica, es el referente al incumplimiento de sus obligaciones económicas por el cónyuge separado o divorciado.

Nos encontramos diariamente ante los órganos judiciales solicitudes de ejecuciones de sentencias de separación y divorcio, donde se pide que se exija, embargue o se utilicen medios, para que por el cónyuge obligado al pago de pensión compensatoria o alimenticia cumpla dicha prestación. Cónyuges que persiguen situaciones de insolvencia, o apa- 
rentan la misma, con la única finalidad de eludir dicha obligación. Son muchos los supuestos que la práctica diaria nos ofrece.

Ya la Circular 3/1986 de la Fiscalía General del Estado llamaba la atención ante el problema de la frecuencia en el incumplimiento de la obligación de alimentos, establecida por la autoridad judicial en los procesos matrimoniales, a favor de los hijos menores o incapacitados.

Ahora bien, ¿era preciso incriminar la conducta del artículo 487 bis? o por el contrario, corresponde su regulación a otros órdenes del Derecho, y en todo caso, el Código Penal era suficiente sin necesidad de la creación de este tipo penal.

Cierto es que el legislador ha pretendido satisfacer reiteradas demandas de algunos sectores sociales, preocupados por la situación que provoca el incumplimiento de las prestaciones por el cónyuge obligado a ello.

\section{Bien jurídico protegido}

Aparece encuadrado como un nuevo tipo de abandono de familia y en consecuencia como un delito contra la seguridad, que persigue el cumplimiento de determinados deberes. El sustraerse de esos deberes la ley lo considera como una falta de seguridad para el tercero siendo éste el bien jurídico protegido.

Se ha mantenido que el bien jurídico protegido es doble pues no sólo se van a proteger los derechos asistenciales derivados de la familia "sino también el orden público en la faceta recogida por el artículo 118 de la Constitución Española = es obligado cumplir las sentencias y demás resoluciones firmes de los jueces y Tribunales" (En este sentido Liro García Pérez en Notas sobre la reforma del abandono de familia y de niños en la L.O. 3/1989, de 21 de junio).

Esta interpretación sobre el bien jurídico protegido, si bien es correcta desde el punto de vista de los fines del nuevo artículo, es consecuencia de la duplicidad reguladora que va a generar este nuevo precepto, pues incrimina conductas ya contempladas en el delito de desobediencia del artículo 237 del Código Penal, que el bien jurídico que protege es el orden público, en cuanto incumplimiento de decisiones de los jueces y tribunales. 


\section{Acción}

La conducta castigada en el artículo 487 bis es puramente de omisión. Se trata de dejar de cumplir las prestaciones económicas a que hace referencia durante tres meses consecutivos o seis meses no consecutivos.

Se ha de impagar prestaciones económicas establecidas en convenio judicialmente aprobado o resolución judicial, en los supuestos de separación, divorcio o declaración de nulidad.

Como característica de las leyes en blanco los elementos objetivos del delito han de extraerse de otros órdenes normativos. Así tendremos que incorporar del ordenamiento jurídico-civil los conceptos que puede contemplar este precepto.

Es necesario que la prestación económica esté establecida en convenio judicial o resolución judicial, con lo cual excluye los convenios o acuerdos escritos que pactan los cónyuges para regular una separación matrimonial de hecho, sin presentarlos ante la autoridad judicial. Exige el artículo que la separación conyugal, se adopte judicialmente, tanto en los procedimientos de separación de consuno, como si es sin mutuo acuerdo.

Al hablar de resolución judicial, extiende el precepto la persecución del incumplimiento, tanto si se ha puesto fin al procedimiento judicial de separación y/o divorcio como si el deber de prestación económica se ha establecido por Auto adoptando medidas previas provisionalísimas de separación, o adoptando medidas provisionales coetáneas.

Entiendo desafortunado el término "cualquier tipo de prestación económica" por la amplitud e imprecisión que genera. Incluye el delito el incumplimiento de la pensión compensatoria del artículo $97 \mathrm{del}$ Código Civil, en favor del cónyuge que le produce desequilibrio económico en relación con la posición del otro, la separación o divorcio; la indemnización recogida para los supuestos de nulidad en el artículo 98; la pensión alimenticia en favor de los hijos del artículo 93; así como las medidas previas o coetáneas del artículo 103 y 104 del mismo cuerpo legal.

Como se ha dicho anteriormente, alcanza las obligaciones tanto si han sido adoptadas judicialmente, como si han sido pactadas en convenio regulador por ambos cónyuges, recogiendo lo establecido en el 
artículo 90 del Código Civil, si bien exige el delito, que el convenio haya sido aprobado judicialmente, con lo que no bastaría con la ratificación ante la presencia judicial del convenio, sino que ha de sustanciarse todo el procedimiento judicial hasta que recaiga la resolución judicial que apruebe el mismo.

El incumplimiento de parte de las obligaciones económicas son subsumibles en el artículo 487 bis. Así cumplir con la pensión compensatoria para el otro cónyuge y no hacerla con la alimenticia para con los hijos, o viceversa, sería constitutivo del delito. No se incluye en este delito las pensiones de alimentos para hijos de padres no casados.

Una de las criticas que ha recibido este delito es que se presta a una interpretación exclusivamente formal, en cuyo caso permite la penalización de simples incumplimientos de obligaciones civiles, sin importar ni valorar cuál sea la situación económica del otro cónyuge o hijos. Será la práctica judicial la que deberá ir contemplando la posible incidencia de estas circunstancias, si bien el precepto no las contempla.

En cuanto al tiempo, se hace preciso que se computen los plazos de tres meses consecutivos o seis meses no consecutivos sin hacerse efectivo el pago de la prestación.

El impago durante un tiempo menor a dichos plazos, si bien no sería constitutivo del delito que estamos estudiando, sí sería delito de desobediencia del artículo 237, con lo que la pena por la conducta sería igual (arresto mayor y multa de 100.000 a 500.000 ptas.).

Como han puesto de manifiesto Muñoz Conde y otros, esta conclusión resulta insatisfactoria en la medida en que se equipara la pena de dos conductas de distinta entidad.

Por ello han propuesto una revisión de la interpretación del delito de desobediencia a estos efectos, a partir de su comparación sistemática con el nuevo delito de impago de pensiones, concluyéndose que su impago por tiempo inferior al señalado en el artículo 487 bis debe ser constitutivo de la falta de desobediencia leve a la autoridad del artículo 570,1 .

No se excluye el delito, ni aún en el supuesto de que el cónyuge que tenga derecho a percibir la prestación, sea el cónyuge culpable de la separación, extremo que si se contempla para el delito de abandono de familia del artículo 487. 


\section{El problema de las cuestiones prejudiciales}

Considero que en el enjuiciamiento de conductas por este delito, se podría suscitar en algún caso, cuestión prejudicial civil al amparo de lo establecido en los artículos 3 a 7 de la Ley de Enjuiciamiento Criminal. Ello porque se está castigando por el impago de un cónyuge de una prestación económica y tendrá que quedar perfectamente acreditado, qué tipo de prestación se incumple y si la obligación permanece vigente. En este sentido, que el cónyuge pierda el derecho a percibir la pensión por alguna de las causas establecidas en el artículo 101 del Código Civil, como pueda ser por el cese de la causa que la motivó, por contraer el acreedor nuevo matrimonio o por vivir maritalmente con otra persona, motivará que el cónyuge obligado a pagar plantee demanda de modificación de medidas según lo establecido en el artículo 90 "in fine". Entiendo que la comisión o no del delito en el caso de que el cónyuge hubiere dejado de abonar la pensión podría quedar supeditada a la cuestión prejudicial civil que nos dirá si el derecho a percibir pensión se había extinguido.

\section{Antijuridicidad}

Especial interés en este punto ofrece la posibilidad de la concurrencia de la circunstancia eximente del estado de necesidad (art. 8,7). Estamos ante el supuesto de impago de la pensión, pues el carecer de medios suficientes y para evitar el mal propio, lesiona bienes jurídicos de otras personas o infringe un deber.

Es admitida esta circunstancia por autores, si bien podría suscitar la duda de si el padre no está obligado a sacrificarse en favor de su hijo. En aplicación del citado artículo, no surge la obligación de sacrificarse toda vez que no quedaría encuadrada en el concepto de "oficio o cargo", contemplado en el mismo.

Sin embargo, téngase como mera reflexión, el hecho de que la pensión alimenticia a favor de hijos, en la mayor parte menores y sin posibilidad de subsistencia por medios propios, lleva implícita una obligación jurídica de protección asumida por los padres y que genera un cierto deber de sacrificio. Ello sin entrar en valoraciones éticas y morales.

La propia Ley de Enjuiciamiento Civil excluye la inembargabilidad 
del salario mínimo interprofesional cuando el objeto sea el pago de alimentos debidos al cónyuge o a los hijos (art. 1449 último párrafo).

En cuanto a la ausencia de antijuridicidad por el consentimiento del sujeto pasivo, el consentimiento del cónyuge es irrelevante en la renuncia que hiciera del derecho a la pensión alimenticia a favor del hijo que estuviera bajo su custodia, habida cuenta que se trata de un derecho irrenunciable.

\section{Culpabilidad}

El dolo exige el conocimiento de la resolución judicial y del incumplimiento, más la voluntad de quebrantar el deber establecido.

Como ha afirmado García Arán, técnicamente es posible la comisión culposa, por ejemplo, en actuaciones descuidadas o negligentes, aunque la notificación de las resoluciones al interesado hace difícil imaginar los supuestos de error de tipo vencible.

También es posible la comisión culposa, si a consecuencia de un error no exculpable, el sujeto activo se cree liberado de las obligaciones de pago de las prestaciones económicas.

\section{Grados de ejecución}

Por lo que respecta a la consumación el problema que plantea es si es necesario el incumplimiento total de las prestaciones.

En primer lugar y a tenor del tipo descrito, considero que no es necesario el incumplimiento total para la consumación del delito. El propio precepto contempla dejar de pagar cualquier tipo de prestación económica.

Y en segundo lugar, las prestaciones distintas a las que pueda estar obligado el cónyuge (alimenticia y compensatoria), protegiendo tanto al cónyuge como al hijo, implica que el incumplimiento de una de ellas, aún cuando se cumpla la otra, conlleve la consumación.

Por último, estimo difícilmente concebibles las formas imperfectas de ejecución. 


\section{Grados de participación}

No cabe la coautoría al tratarse de obligaciones que incumben estrictamente al sujeto activo.

Sí es posible la inducción.

\section{Concurso de Leyes}

Se plantea un concurso de leyes entre los distintos tipos de abandono de familia y el delito objeto de este trabajo. Dicho concurso por razones de especialidad se resolverá en favor del delito de impago de prestaciones.

\section{Pena}

Se castiga con la pena de arresto mayor y multa de 100.000 a 500.000 pesetas.

Llama la atención que en el delito de abandono de familia del artículo 487,2, dejar de prestar la asistencia indispensable para el sustento a sus descendientes..., se castiga con la pena de arresto mayor en su grado máximo y multa de 100.000 a 1.000 .000 de pesetas. Por esta razón, Zugaldía señala que se ha convertido este delito en un tipo atenuado de abandono de familia.

No contempla la posibilidad que el Tribunal pueda tomar medidas, acordando la privación del derecho de patria potestad o de tutela que tuviere el reo.

\section{Delito Público}

Se trata de un delito perseguible de oficio. El sujeto pasivo no tendrá disponibilidad sobre la acción penal.

Asimismo, no cabe el perdón de la parte ofendida.

Es un punto controvertido y criticado de este delito. Sorprende que el delito de abandono de familia sea perseguible a instancia de parte y que el perdón extinga la responsabilidad, (último párrafo del artículo 487), y sin embargo no se prevea para este delito. 


\section{Conclusiones}

Se han esbozado algunas de las líneas de este nuevo delito.

La principal crítica que ha recibido es que resucita la denominada "prisión por deudas", contraria de una parte al art. 11 del Pacto Internacional de Derechos Civiles y Políticos (19 de diciembre de 1966), y contrario a la Constitución Española, artículo 25,3.

Se mantiene, que es contrario al principio de intervención mínima. Que el Código Penal ya tenía soluciones para afrontar el incumplimiento de las resoluciones judiciales y subsiguiente impago de prestaciones. En este sentido, el segundo párrafo del artículo 487 hubiera podido cumplir la finalidad que persigue el nuevo delito. El delito de desobediencia del artículo 237, podría ser suficiente para la persecución de esta figura delictiva, o en todo caso, como afirma Bajo Fernández, si resultara ineficaz con carácter general, hubiera sido el momento oportuno para su modificación en orden a concederle mayor eficacia. También podrían haber conseguido la finalidad de este delito, como indica el citado autor, los delitos de estafa y alzamiento de bienes, convenientemente aplicados.

Otra crítica recibida es la que mantiene la dudosa constitucionalidad del precepto, ya que deja sin protección este tipo, a los hijos extramatrimoniales, violando el principio de igualdad ante la ley. (art. 14 de la Constitución).

Tambien se ha afirmado, sirviendo de pauta el delito de abandono de familia, que de una parte, mientras en éste no comete delito con respecto al cónyuge culpable de la sepración, en el artículo 487 bis, no se contempla. $\mathrm{Y}$ de otra parte, mientras en el delito de abandono de familia es necesario que no se preste la asistencia indispensable para el sustento, en el 487 bis, no importa cuál sea la situación económica de los hijos.

Cierto es en conclusión, que como afirma Quintano la sanción de lo penal ha de limitarse y se limita, en efecto a las situaciones más extremas de ilicitud. Ante estas conductas con típica naturaleza de ilicitud civil criminalizada, entiendo que el Código Penal posee ya tipos que quizás hubieran hecho innecesaria la incorporación de este delito. Las soluciones ante el posible incumplimiento, podían venir a su vez de 
una potenciación de las garantías previstas en el artículo 90 "in fine" del Código Civil.

No obstante, la práctica requiere una gran protección a quienes en las crisis matrimoniales padecen las consecuencias de la insolidaridad del obligado, como el propio preámbulo de la Ley ha puesto de manifiesto. 